\title{
Biossíntese de vanilina pelo fungo Pycnoporus sanguineus MIP 95001
}

\author{
Sabrina Moro Villela Pacheco * \\ Ayres Ferreira Morgado \\ Agenor Furigo Junior \\ Universidade Federal de Santa Catarina, Departamento de Engenharia Química \\ Campus Universitário Trindade, CEP 88040-900, Florianópólis - SC, Brasil \\ * Autor para correspondência \\ sabrinavillela@gmail.com
}

Submetido em 25/10/2012

Aceito para publicação em 06/06/2013

\section{Resumo}

A vanilina (substância popularmente conhecida como aroma de baunilha) é um dos compostos mais utilizados, principalmente pelas indústrias alimentícias e farmacêuticas. Esta substância pode ser obtida da orquídea Vanilla planifolia, porém, este é um processo oneroso e demorado. Por esse motivo, outros métodos para a obtenção da vanilina vêm sendo estudados. Dentro deste contexto, o objetivo deste trabalho foi estudar a biossíntese de vanilina por três isolados de Pycnoporus sanguineus através do uso de ácido vanílico como precursor. Os isolados foram cultivados em placas de Petri com meio ágar batata dextrose. Fragmentos destes cultivos foram inoculados em Erlenmeyers com meio líquido de caldo de batata e $0,3 \mathrm{~g} . \mathrm{L}^{-1}$ de ácido vanílico. Os frascos permaneceram em shaker por oito dias a $28^{\circ} \mathrm{C}$ e $120 \mathrm{rpm}$. Foram retiradas alíquotas diárias $\left(0,8 \mathrm{~mL} \cdot \mathrm{dia}^{-1}\right)$ para análise de vanilina, glicose, fenois totais, enzima lacase e proteínas totais. Os resultados revelaram que apenas a cepa MIP 95001 promoveu a biossíntese da vanilina. A maior concentração de vanilina foi detectada no quarto dia de cultivo $\left(8,75 \mathrm{mg} . \mathrm{dL}^{-1}\right)$. De forma geral, os resultados apresentados ilustram a possibilidade de biossintetizar a vanilina pelo Pycnoporus sanguineus (MIP 95001), evidenciando uma possível rota biotecnológica para a produção deste aroma.

Palavras-chave: Biossíntese; Pycnoporus sanguineus; Vanilina

\section{Abstract}

Biosynthesis of vanillin by the fungus Pycnoporus sanguineus MIP 95001. Vanillin (a substance popularly known as vanilla flavor) is one of the most widely used compounds, mainly by food and pharmaceutical industries. This substance can be obtained from the orchid Vanilla planifolia, but this is costly and time consuming. Thus, other methods for obtaining vanillin have been studied. Within this context, the aim of this work was to study the biosynthesis of vanillin by three strains of Pycnoporus sanguineus through the use of vanillic acid as a precursor. The strains were cultured in Petri dishes with a potato dextrose agar medium. Fragments of the media with the fungus were then inoculated in Erlenmeyer flasks with a liquid medium of potato broth and $0.3 \mathrm{~g}$.. $\mathrm{L}^{-1}$ of vanillic acid. The flasks remained in a shaker for eight days at $28^{\circ} \mathrm{C}$ and $120 \mathrm{rpm}$. Samples were withdrawn once a day $\left(0.8 \mathrm{~mL}^{\left.-d_{a}{ }^{-1}\right)}\right.$ for analysis of vanillin, glucose, total phenols, total proteins, and laccase. The results showed that only the MIP 95001 strain promoted the biosynthesis of vanillin. The highest 
concentration of vanillin was detected on the fourth day of cultivation $\left(8.75 \mathrm{mg} \cdot \mathrm{dL}^{-1}\right)$. The results illustrate the ability to biosynthesize vanillin using Pycnoporus sanguineus (MIP 95001), which suggests a possible route for the biotechnological production of this flavor.

Key words: Biosynthesis; Pycnoporus sanguineus; Vanillin

\section{Introdução}

A vanilina ou 4-hidróxi-3-metoxibenzaldeído é um composto aromático largamente utilizado como flavorizante para alimentos e em algumas fragrâncias (WALTON et al., 2003). A vanilina é obtida tradicionalmente da vagem de uma orquídea tropical, a Vanilla planifolia. Devido ao processo de extração da vanilina, esta orquídea é a única de interesse comercial fora do contexto ornamental. A publicação desde gênero de orquídea foi feita pela primeira vez, seguindo o sistema de Linneus, por Miller, em seu "Gardener's Dictionary", datado em 1754, com o nome latinizado de Vanilla (CLASSIC ENCYCLOPEDIA, 1911).

A vanilina ocorre em quantias traço em outras plantas como o tabaco. No entanto, as vagens desta orquídea ainda continuam sendo a principal fonte natural de vanilina. Em 1999, foi relatado que, embora mais de 12.000 toneladas de vanilina tenham sido produzidas anualmente, menos de $1 \%$ foi extraída da planta, sendo a quantidade restante sintetizada. Nesse mesmo ano, o valor da vanilina natural oscilou entre $\$$ $1.200,00$ e $\$ 4.000,00$ por $\mathrm{kg}$, em contraste com o preço da vanilina sintética, cujo kg custou menos de $\$ 15,00$ (LOMASCOLO et al., 1999). Os números citados e o incentivo ao aumento no consumo de produtos naturais, demonstram o interesse industrial em se encontrar novas tecnologias para a produção da vanilina natural. Um caminho vantajoso para a obtenção de produtos naturais é o uso de processos biotecnológicos envolvendo microrganismos, desde que a legislação incorpora o termo "produtos naturais" como aqueles produzidos por fontes biológicas: células vivas ou seus componentes, incluindo as enzimas (LESAGE-MEESSEN et al., 1996). Alguns estudos têm demonstrado que a vanilina pode ser produzida biotecnológicamente a partir de vários tipos de microrganismos e precursores fenólicos. Para exemplificar essa afirmação é possível citar o trabalho de Bonnin et al. (2001), que obtiveram vanilina através do uso sequencial de Aspergillus niger e Pycnoporus cinnabarinus. Neste caso, o Aspergillus niger foi usado para promover a liberação do precursor ácido ferúlico a partir de meios constituídos por farelo de milho e polpa de beterraba. Yoshida et al. (1997) produziram vanilina a partir do precursor vanilil-amina utilizando as enzimas amino oxidase de Aspergillus niger e monoamino oxidase de Escherichia coli. Barbosa et al. (2008) realizaram a fermentação em estado sólido de cascas de coco usando o basidiomiceto Phanerochaete chrysosporium. Através da realização de um planejamento experimental os autores otimizaram a produção de vanilina após $24 \mathrm{~h}$ de fermentação. Stentelaire et al. (2000) estudaram a produção de vanilina através de ácido vanílico com Pycnoporus cinnabarinus em reatores do tipo agitado mecanicamente e air-lift. Os melhores resultados foram obtidos com o reator agitado mecanicamente nas condições de menor disponibilidade de oxigênio dissolvido, agitação suave, alta produção de dióxido de carbono e baixa taxa de crescimento do microrganismo. Outros substratos fenólicos, tais como o engenol (OVERHAGE et al., 2006) e o isoeugenol (SHIMONI et al., 2000) também foram estudados para a produção biotecnológica de vanilina.

Conforme exposto acima, o Pycnoporus cinnabarinus é um fungo bastante estudado para a produção de vanilina, porém, ele é nativo do hemisfério norte, crescendo especialmente na América do Norte e Europa. No Brasil, assim como em outras regiões do hemisfério sul, é possível encontrar uma espécie com características muito semelhantes, o Pycnoporus sanguineus. O fungo Pycnoporus sanguineus é conhecido popularmente como "orelha de pau" e faz parte da família Polyporaceae, Aphyllophorales, Basidiomycetes (NOBLES; FREW, 1962). É um fungo saprófita de lento crescimento sendo utilizado como medicamento por indígenas da América Latina e África. Na Amazônia, esse fungo é utilizado pelos Caibis para evitar pesadelos e pelos Txucarramães, como alimento. 
No México é utilizado como anti-inflamatório e contra verrugas. Na África, mulheres indígenas Dahomey o utilizam para curar certos problemas decorrentes da menopausa e outras enfermidades do ventre. Em comunidades do interior de Santa Catarina, seu uso é recomendado para o tratamento de feridas supurativas (SMÂNIA et al., 1995).

Conforme já citado anteriormente, o Pycnoporus sanguineus é um fungo pertencente à classe dos Basidiomicetos, que por sua vez, são classificados com base nas diferenças dos respectivos padrões de degradação da madeira, levando-se em consideração características macroscópicas de degradação. Assim podem ser divididos em fungos de degradação branca (white-rot), degradação marrom (brown-rot) e degradação macia (soft-rot) (SOARES, 1998).

A degradação da lignina pelos fungos de degradação branca ocorre de forma mais rápida se comparado a outros organismos responsáveis pela degradação da lignina na natureza. No entanto, o substrato de crescimento para esses fungos não é constituído somente por lignina, mas também por hemicelulose e celulose. Esses fungos degradam a lignina através de um complexo sistema enzimático lignolítico, o qual é observado na forma de metabolismo secundário, ou seja, são formados quando o crescimento do fungo decresce em função da depleção da fonte de carbono e nitrogênio (TUOMELA et al., 2000). Existe uma série de enzimas envolvidas na degradação da lignina, tais como ligninas peroxidases (EC 1.11.1.14), peroxidases dependente de Mn (EC 1.11.1.13), lacases (EC 1.10.3.2) e aril álcool oxidases (EC 1.1.3.7) (HATAKKA, 1994). As enzimas citadas são classificadas como oxirredutases e atuam despolimerizando a lignina através de um mecanismo de reações não específicas.

Dessa forma, levando-se em consideração as características do fungo em questão e o fato do mesmo agir preferencialmente sobre a lignina (polímero formado basicamente por precursores fenólicos), o objetivo deste trabalho foi estudar a biossíntese da vanilina utilizando três isolados de Pycnoporus sanguineus e o ácido vanílico como precursor.

\section{Material e Métodos}

Os fungos utilizados nos cultivos foram três cepas distintas de Pycnoporus sanguineus: MIP 20001 (Florianópolis - SC), MIP 95001 (Florianópolis SC) e MIP 95002 (Imbituba - SC). As cepas testadas foram doadas pelo Laboratório de Antibióticos do Departamento de Microbiologia e Parasitologia (MIP) da Universidade Federal de Santa Catarina.

Os microrganismos foram mantidos em meio de cultivo constituído por dextrose, batata e ágar (42 g.L.-1) (Difco). A manutenção das linhagens foi realizada em tubos de ensaio contendo o mesmo meio supracitado, inclinado a $25^{\circ} \mathrm{C}$ por 15 dias e posteriormente mantidos em refrigerador a $4^{\circ} \mathrm{C}$.

Para os estudos de biossíntese os fungos foram previamente cultivados em Placas de Petri com meio dextrose, batata e ágar por 10 dias a $28^{\circ} \mathrm{C}$. Na sequência, discos de $1 \mathrm{~cm}$ de raio foram removidos das culturas e introduzidos em Erlenmeyers de $250 \mathrm{~mL}$ contendo $50 \mathrm{~mL}$ de meio líquido de caldo de batata $\left(200 \mathrm{~g} . \mathrm{L}^{-1}\right.$ de batata e 20 g.L.-1 de glicose) com 0,3 g.L.- de ácido vanílico P.A. (Sigma). Erlenmeyers com o mesmo meio, porém, sem a adição do ácido vanílico, foram utilizados como controle negativo. Após a inoculação dos fungos, os frascos foram acondicionados em shaker rotacional por oito dias a $28{ }^{\circ} \mathrm{C}$. Durante o período de incubação, alíquotas de $0,8 \mathrm{~mL} \cdot \mathrm{dia}^{-1}$ foram retiradas das culturas para análise de proteínas totais, fenois totais, enzima lacase, glicose e vanilina.

A determinação de proteínas totais foi realizada através do Kit para determinação das proteínas totais da marca ANALISA ${ }^{\circledR}$. O princípio deste método se baseia no fato das ligações peptídicas das proteínas reagirem com íons cúpricos em meio alcalino (reagente de Biureto) formando um complexo que absorve em $545 \mathrm{~nm}$ e que por sua vez, é diretamente proporcional à concentração de proteínas na amostra.

A dosagem de fenois totais foi realizada através do método de Folin-Ciocalteu. O método se baseia na reação de compostos aromáticos contendo grupos hidróxi com o reagente Folin-Ciocalteu (tungstato de sódio e molibdato de sódio), que gera um produto que absorve em $700 \mathrm{~nm}$ (APHA/AWWA, 1989). 
A determinação de glicose foi realizada através do Kit para determinação de glicose da marca ANALISA ${ }^{\circledR}$. $\mathrm{O}$ princípio deste método se baseia na reação entre o peróxido de hidrogênio com a $\mathrm{D}$-glicose. $\mathrm{O}$ produto formado a partir desta reação é o D-ácido glucônico que reage com hidróxibenzoato, 4-aminofenazona e peróxido de hidrogênio para formar um complexo quinona que absorve em $500 \mathrm{~nm}$. Dessa forma, a intensidade da cor é proporcional à concentração de glicose da amostra.

A determinação da atividade da lacase foi realizada utilizando o método de Ander e Eriksson (1976). Esse método baseia-se na oxidação da siringaldazina para sua forma quinona que apresenta absorção em 525 $\mathrm{nm}\left(\varepsilon=65000 \mathrm{M}^{-1} \mathrm{~cm}^{-1}\right)$ em tampão tartarato $0,1 \mathrm{M}$ $\mathrm{pH} 4,0$. A amostra submetida à análise de lacase foi pré-incubada com $50 \mu \mathrm{L}$ de uma solução de catalase $\left(\right.$ Novozymes $^{\circledR}$ ) para a redução de interferência de peroxidase na análise. Para determinação da atividade de lacase, foram incubados em cubeta de quartzo de 1 $\mathrm{mL}, 500 \mu \mathrm{L}$ de tampão fosfato $(0,1 \mathrm{M}) \mathrm{pH} 4,0,50 \mu \mathrm{L}$ do caldo bruto da cultura fúngica previamente filtrada com papel filtro Whatman, n. 1 e $25 \mu \mathrm{L}$ de solução alcoólica de siringaldazina $\left(0,5\right.$ g. $\left.\mathrm{L}^{-1}\right)$, por $5 \mathrm{~min}$ a $25^{\circ} \mathrm{C}$. Para o cálculo da atividade enzimática foi utilizada a Equação (1) (OHLWEILER, 1980):

$$
\text { (1) } c=\frac{A}{(\varepsilon \times d)} \times f
$$

Onde:

$c=$ concentração

$A=$ absorbância em $525 \mathrm{~nm}$

$\varepsilon=$ absortividade

$d=$ caminho ótico $1 \mathrm{~cm}$

$f=$ fator de diluição

Os dados foram obtidos com o auxílio de um espectrofotômetro Hewlett-Packard.
Uma unidade de atividade enzimática $\left(U \cdot \mathrm{mL}^{-1}\right)$ foi determinada como a quantidade de produto formado pela oxidação de $1 \mu \mathrm{M}$ de substrato por minuto em 1 $\mathrm{mL}$ de solução.

A vanilina foi detectada através do uso de um cromatógrafo a gás da marca CIOLA \& GREGORI modelo CG 90 equipado com detector de ionização de chama e coluna HP-1 (Crosslinked Methyl Siloxane $30 \mathrm{~m} \times 0,53 \mathrm{~mm} \times 1,5 \mathrm{~mm}$ ) acoplado a um microcomputador, onde foi realizada a integração dos picos dos cromatogramas obtidos. As temperaturas utilizadas para a coluna, o injetor e o detector foram respectivamente de 180,200 e $230^{\circ} \mathrm{C}$. O fluxo do gás de arraste nitrogênio foi de $25 \mathrm{~mL} \cdot \mathrm{min}^{-1}$. O volume de amostra (diluída 10X) injetada no cromatógrafo foi de $1,0 \mu \mathrm{L}$. A realização da curva de calibração foi realizada através do uso da vanilina P.A. (Sigma).

\section{Resultados}

Conforme mencionado anteriormente, os meios de cultivo constituídos por caldo de batata, 0,3 g.L $\mathrm{L}^{-1}$ de ácido vanílico e o microrganismo inoculado, foram adicionados em shaker rotacional por 8 dias. Das três cepas testadas (Figura 1), a única que converteu ácido vanílico à vanilina foi a MIP 95001. Através da Figura 2 é possível visualizar o cromatograma obtido após injeção de uma das amostras de caldo bruto da cultura fúngica do MIP 95001 previamente filtrada com papel filtro Whatman, n. 1. em cromatógrafo gasoso. É possível visualizar o pico de vanilina com tempo de retenção de 3,147 min. Os resultados referentes às análises de proteínas totais, fenois totais, enzima lacase, glicose e vanilina para esta cepa podem ser visualizados na Figura 3. 
FIGURA 1: Cepas de Pycnoporus sanguineus utilizadas na pesquisa para produção de vanilina.
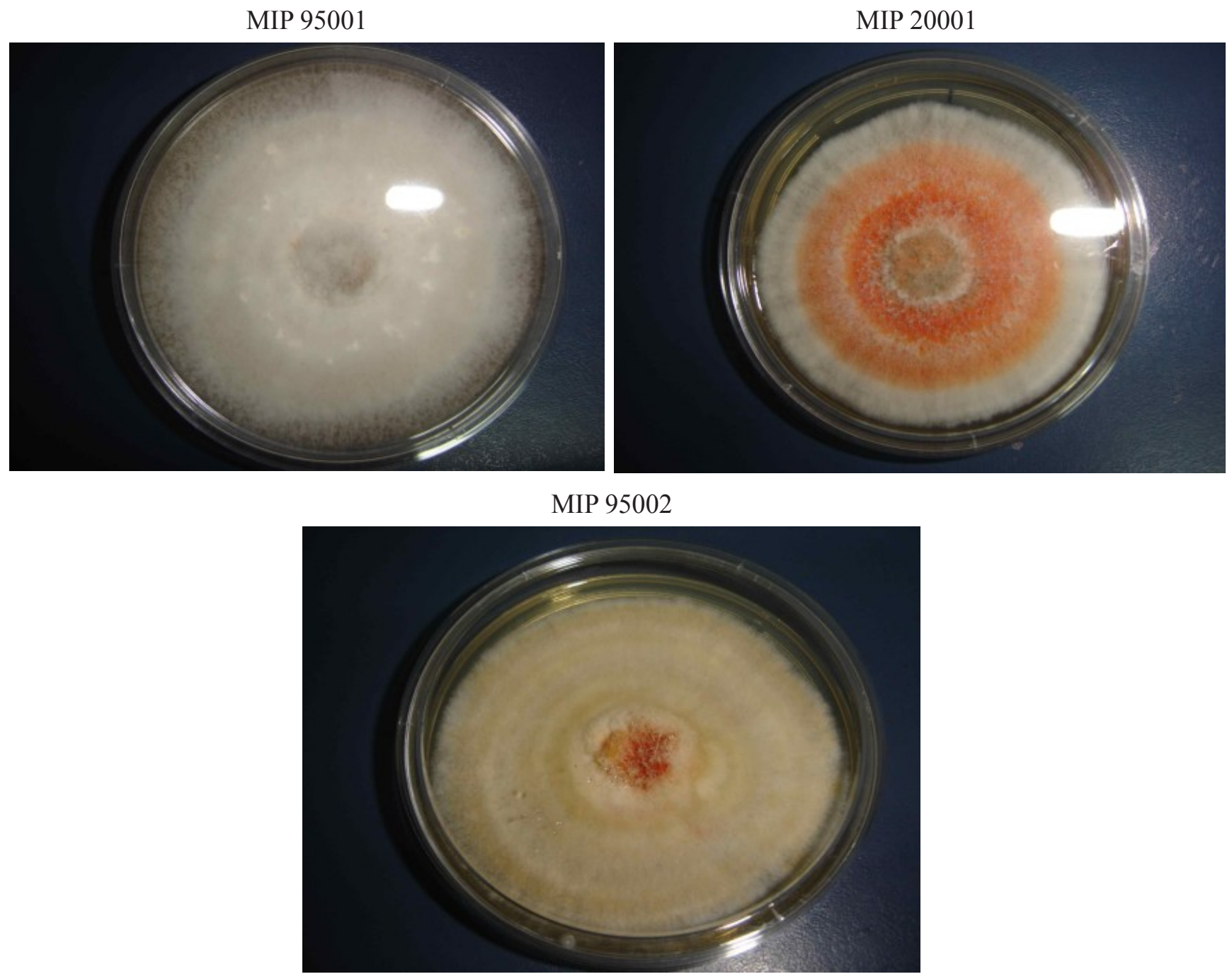

FIGURA 2: Cromatograma do caldo bruto de Pycnoporus sanguineus (MIP 95001) após o quarto dia de incubação com meio de cultivo basal contendo 3 g.L ${ }^{-1}$ de ácido vanílico. Fase estacionária da coluna HP-1 (Crosslinked Methyl Siloxane).

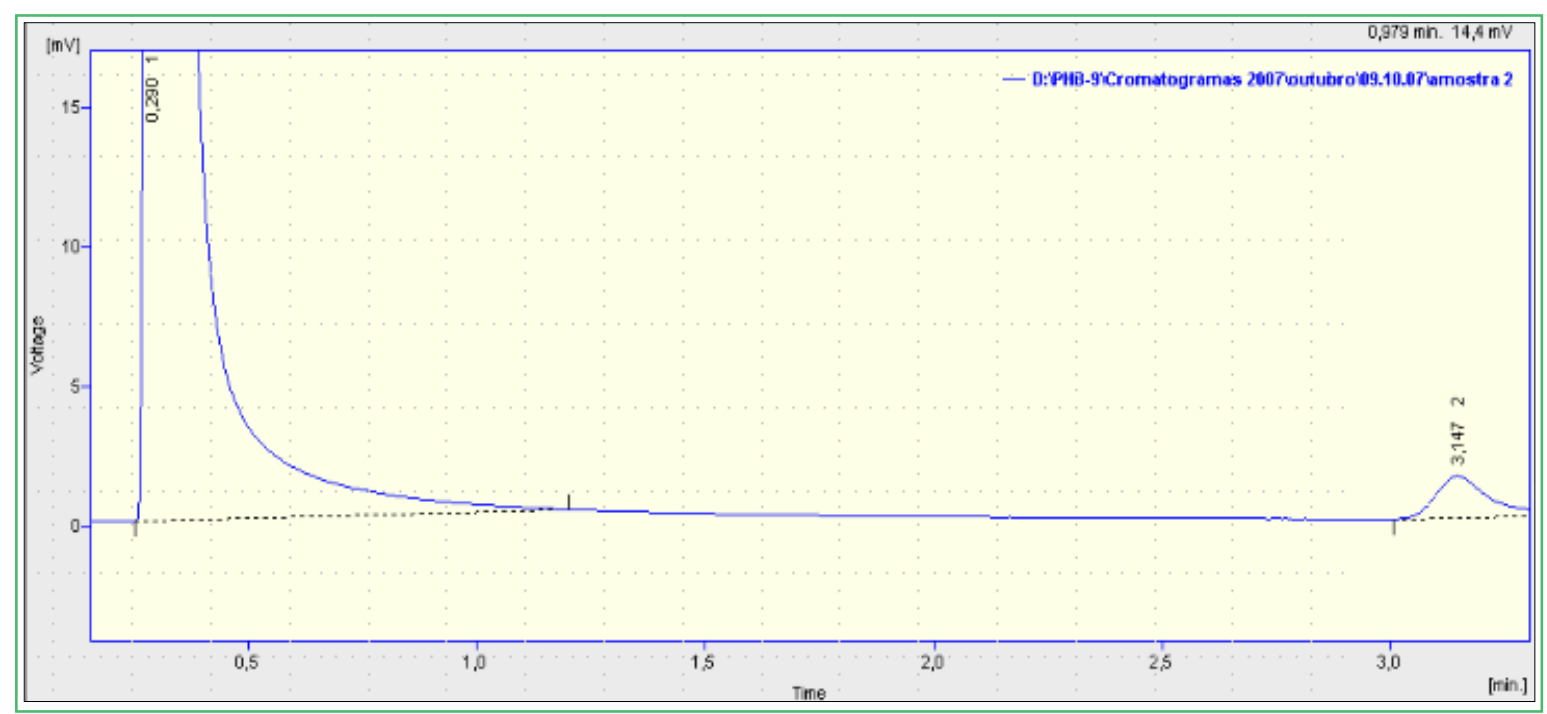


FIGURA 3: Resultados referentes às análises de: (a) enzima lacase e glicose e (b) vanilina, fenois totais e proteínas totais das alíquotas retiradas diariamente do cultivo líquido do Pycnoporus sanguineus (MIP 95001). Os pontos dos gráficos representam a média dos valores das análises realizadas em triplicata.

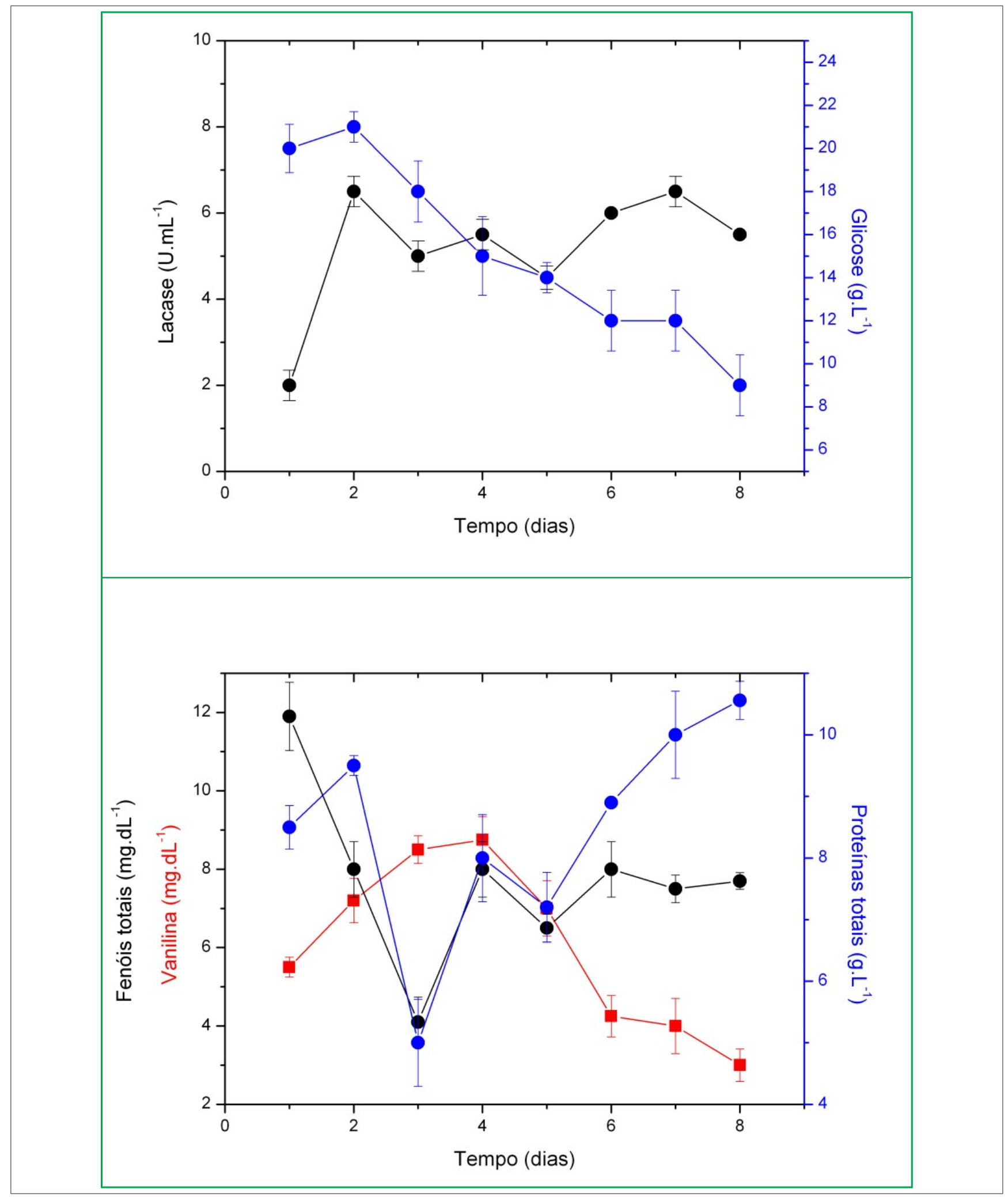




\section{Discussão}

Através dos resultados ilustrados na Figura $3 b$ foi possível observar que houve um aumento até o quarto dia de cultivo, onde foi detectada a maior produção de vanilina. Na sequência, a concentração de vanilina voltou a decrescer. Esse evento possivelmente esteja relacionado com a produção de lacase pelo Pycnoporus sanguineus (HATAKKA, 1994). Esse fungo é conhecido por produzir grandes quantidades dessa enzima, que por sua vez, está associada à biodegradação de compostos fenólicos (TROVASLET et al., 2007). Lesage-Meessen et al. (1996), buscaram contornar esse evento em seu trabalho sobre produção de vanilina através de ácido vanílico, utilizando uma cepa de Pycnoporus cinnabarinus deficiente de lacase. Outra possibilidade, ilustrada no trabalho de Lesage-Meessen et al. (1996), trata da adição de celobiose durante o processo de fermentação, que acarretou em um aumento na produção de vanilina. Esse evento foi explicado pelo fato do aumento da fonte de carbono do meio, acarretar a diminuição da produção de enzimas de stress nutricional, como as lacases. Stentelaire et al. (2000), também promoveram o aumento da produção de vanilina com a adição da resina seletiva XAD-2, que absorve a mesma do meio. Através da diminuição da concentração de vanilina no meio, ocorre o aumento da conversão de ácido vanílico para vanilina pelo fungo, pois se sabe que a vanilina é tóxica em uma concentração acima de 1 g. $\mathrm{L}^{-1}$ para os microrganismos de maneira geral (LOPEZMALO et al., 1997).

Um interessante fato observado foi de que a cepa MIP 95001, produtora de vanilina, foi a única que inicialmente não produziu pigmentação laranja. Esta constatação foi realizada visualmente e de forma qualitativa conforme apresentado por Duarte et al. (2008). Este fungo é facilmente reconhecido por sua intensa cor laranja avermelhada. Ele produz cerca de sete pigmentos, sendo a cinabarina o mais conhecido deles, por suas propriedades antibióticas (SMÂNIA et al., 1995). O trabalho de Smânia et al. (1997) ilustra que os aumentos de $\mathrm{pH}$, aumento da concentração de nitrogênio e presença de luz, estão intrinsecamente relacionados ao aumento da concentração da cinabarina. Dessa forma, os fatores de stress em geral induzem à produção deste metabólito secundário. Tais informações podem ser relacionadas ao fato, de que, durante o cultivo submerso da cepa de Pycnoporus sanguineus MIP 95001, uma coloração laranja passou a ser observada a partir do terceiro dia de fermentação nos discos do fungo, adicionados ao meio de cultivo, conforme ilustrado na Figura 4. Este efeito pode estar

FIGURA 4: Aspecto dos discos de Pycnoporus sanguineus (MIP 95001) no meio líquido após três dias de cultivo.

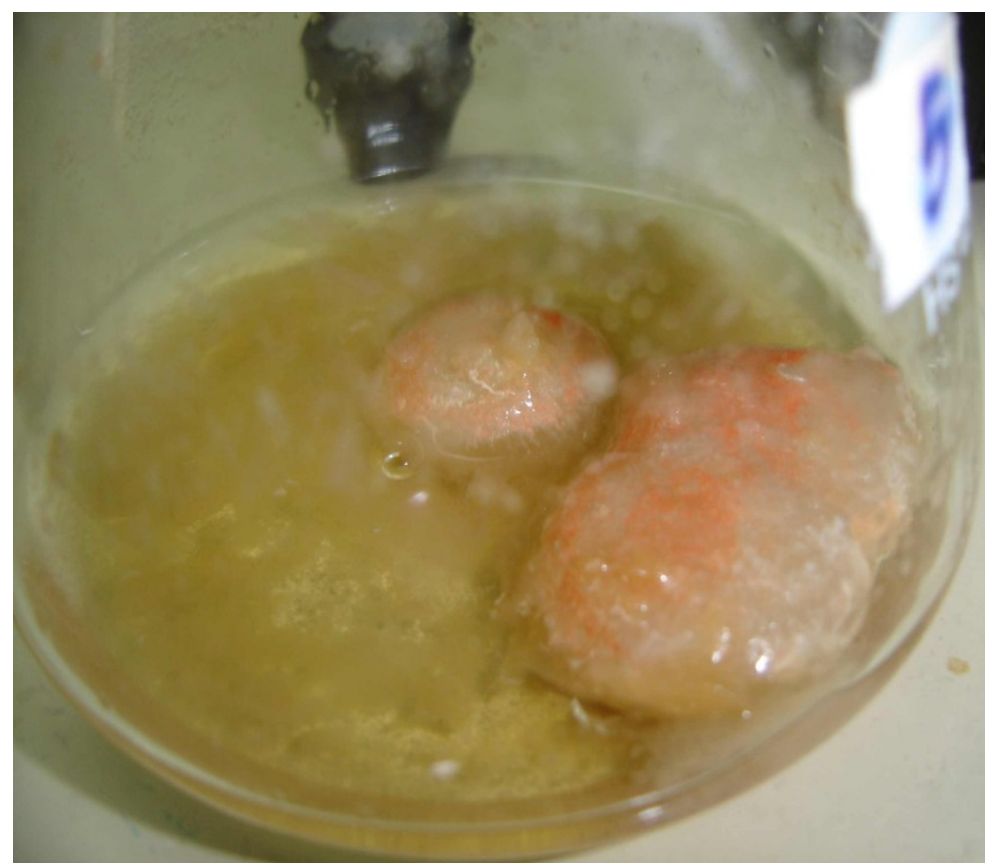


relacionado ao stress provocado ao fungo devido a adição do ácido vanílico e consequente, produção de vanilina. Além disso, curiosamente também foram detectados maiores valores de atividade enzimática de lacase nos cultivos das cepas de Pycnoporus sanguineus MIP 20001 e MIP 95002. Dessa forma, é provável que a cepa MIP 95001 possua a característica de produzir quantidades menores de tal enzima, fazendo com que a mesma só tenha seus valores de atividade mais elevados, sob indução com a adição de um composto fenólico. $\mathrm{O}$ fato de determinados tipos fungos da classe dos Basidiomicetos serem induzidos à produção de lacase, quando incubados com compostos fenólicos, já é um comportamento conhecido e amplamente divulgado (FARNET et al., 2004; GARCIA et al., 2006; SHRADDHA et al., 2011).

Em suma, os resultados revelaram que houve um pico de produção de vanilina de $8,75 \mathrm{mg}$.dL $\mathrm{LL}^{-1}$ no quarto dia de fermentação. Também foi possível verificar uma relação entre a produção de vanilina e a produção de lacase, pois de forma geral, à medida que a concentração de vanilina no meio sofreu aumento, a atividade da enzima lacase também foi aumentando, concomitante ao aumento de proteínas totais. Esse comportamento possivelmente ocorre devido as lacases catalisarem a biodegradação de compostos fenólicos nos meios de cultivo e consequentemente, promoverem a redução do fenol de interesse. Em alguns trabalhos pode ser observado que a própria vanilina é utilizada na indução da produção de lacase (SOUZA et al., 2004; CAVALLAZZI et al., 2005). Dessa forma, é possível evidenciar, através dos resultados apresentados neste trabalho, que a biossíntese de vanilina pelo Pycnoporus sanguineus pode ser uma rota biotecnológica alternativa para a produção deste aroma. Entretanto, ainda são necessários mais estudos, especialmente no que tange a otimização do processo, trabalhando em termos de deslocamento da reação com a adição de maiores concentrações do reagente ácido vanílico ou possibilidade de retirada da vanilina para evitar indução da produção de lacase e favorecer a produção do aroma.

\section{Referências}

ANDER, P.; ERIKSSON, K. The importance of phenol oxidase activity in lignin degradation by the white-rot fungus Sporotrichum pulverulentum. Archives of Microbiology, Berlin, v. 109, p. 1-8, 1976.

APHA/AWWA. Standard methods for examination of water and waterwater 5550. 5.58-5. 17. ed. New York: American Public Health Association, 1989. 69 p.

CLASSIC ENCYCLOPEDIA. 1911. Disponível em: <http:// www.1911 encyclopedia.org/Vanilla>. Acesso em: 25 out. 2012.

BARBOSA, E. S.; PERRONE, D.; VENDRAMINI, A. L. A.; LEITE, S. G. F. Vanillin production by Phanerochaete chrysosporium grown on green coconut agro-industrial husk in solid state fermentation. BioResources, Raleigh, v. 3, p. 10421050, 2008.

BONNIN, E.; BRUNEL, M.; GOUY, Y.; LESAGE-MEESSEN, L.; ASTHER, M.; THIBAULT, J. F. Aspergillus niger I-1472 and Pycnoporus cinnabarinus MUCL39533, selected for the biotransformation of ferulic acid to vanillin, are also able to produce cell wall polysaccharide-degrading enzymes and feruloyl esterases. Enzyme and Microbial Technology, Amsterdam, v. 8, p. 70-80, 2001.

CAVALLAZZI, J. R.; KASUYA, C. M.; SOARES, M. A. Screening of inducers for laccase production by Lentinula edodes in liquid medium. Brazilian Journal of Microbiology, São Paulo, v. 36, p. 383-387, 2005.

DUARTE, J. B.; MAS DIEGO, S. M.; VILLELA, S. M.; MORGADO, A. F.; FURIGO, A. Comparative study of mycelial growth and production of cinnabarin by different strains of Pycnoporus sanguineus. BioFar: Revista de Biologia e Farmácia, João Pessoa, v. 2, p. 1-5, 2008.

GARCIA, T. A.; SANTIAGO, M. F.; UlHOA, C. J. Properties of laccases produced by Pycnoporus sanguineus induced by 2,5-xylidine. Biotechnology Letters, Dordrecht, v. 28, p. 633-636, 2006.

FARNET, A.; CRIQUET, S.; CIGNA, M.; GIL, G.; FERRÉ, E. Purification of a laccase from Marasmius quercophilus induced with ferulic acid: reactivity towards natural and xenobiotic aromatic compounds. Enzyme and Microbial Technology, Amsterdam, v. 34, p. 549-554, 2004

HATAKKA, A. Lignin-modifying enzymes from selected whiterot fungi: production and role in lignin degradation. FEMS Microbiology Reviews, Lausanne, v. 13, p. 125-135, 1994.

LESAGE-MEESSEN, L.; DELATTRE, M.; HAON, M.; THIBAULT, J. F.; CECCALDI, B. C.; BRUNERIE, P.; ASTHER, M. A two-step bioconversion process for vanillin production from ferulic acid combining Aspergillus niger and Pycnoporus cinnabarinus. Journal of Biotechnology, Bielefeld, v. 50, p. 107113, 1996

LOMASCOLO, A.; STENTELAIRE, C.; ASTHER, M.; LESAGEMEESSEN, L. Basidiomycetes as new biotechnological tools to generate natural aromatic flavours for the food industry. Trends in Biotechnology, Amsterdam, v. 17, p. 282-289, 1999.

LOPEZ-MALO, A.; ALZAMORA, S. M.; ARGAIZ, A. Effect of vanillin concentration, $\mathrm{pH}$ and incubation temperature on Aspergillus flavus, Aspergillus niger, Aspergillus ochraceus and 
Aspergillus parasiticus growth. Food Microbiology, SummitArgo, v. 14, p. 117-124, 1997.

NOBLES, M. K.; FREW, B. P. Studies in wood inhabiting hypmenomycetes. V. The genus Pycnoporus Karst. Canadian Journal of Botany, Ontário, v. 40, p. 987-1016, 1962.

OHLWEILER, O. A. Química analítica quantitativa. v. 3. 2. ed. Rio de Janeiro: Livros Técnicos e Científicos Editora S.A., 1980. $685 \mathrm{p}$.

OVERHAGE, J.; STEINBUCHEL, A.; PRIEFERT, H. Harnessing eugenol as a substrate for production of aromatic compounds with recombinant strains of Amycolatopsis sp. HR167. Journal of Biotechnology, Bielefeld, v. 15, p. 369-376, 2006.

SHIMONI, E.; RAVID, U.; SHOHAM, Y. Isolation of a Bacillus sp. capable of transforming isoeugenol to vanillin. Journal of Biotechnology, Bielefeld, v. 78, p. 1-9, 2000.

SHRADDHA, R. S.; SIMRAN S.; MOHIT K.; KUMAR, A. Laccase: microbial sources, production, purification, and potential biotechnological applications. Enzyme Research, New York, v. 2011, p. 1-11, 2011.

SMÂNIA, A.; SMÂNIA, E. F. A.; CRUZ, F. S.; BENCHETRIT, L. C. Growth and production phases of Pycnoporus sanguineus. Revista de Microbiologia, São Paulo, v. 26, p. 302-306, 1995.

SMÂNIA, E. F. A.; SMÂNIA, A. JR.; LOGUERCIO-LEITE, C.; GIL, M. L. Optimal parameters for cinnabarin synthesis by Pycnoporus sanguineus. Journal of Chemical Technology \& Biotechnology, London, v. 70, p. 57-59, 1997.
SOARES, C. H. L. Estudos mecanísticos da degradação de efluentes de indústrias de papel e celulose por fungos Basidiomicetos degradadores de madeira. 1998. $133 \mathrm{f}$. Tese (Doutorado em Ciências) - Universidade Estadual de Campinas, Campinas. 1998.

SOUZA, C. G. M.; TYCHANOWICZ, G. K.; SOUZA, D. F.; PERALTA, R. M. Production of laccase isoforms by Pleurotus pulmonarius in response to presence of phenolic and aromatic compounds. Journal of Basic Microbiology, Berlin, v. 44, p. 129136, 2004.

STENTELAIRE, C.; LESAGE-MEESSEN, L.; ODDOU, J.; BERNARD, O.; CECCALDI, B. C.; ASTHER, M. Design of a fungal bioprocess for vanillin production from vanillic acid at scalable level by Pycnoporus cinnabarinus. Journal of Bioscience and Bioengineering, Osaka, v. 89, p. 223-230, 2000.

TROVASLET, M.; ENAUD, E.; GUIAVARC'H, Y.; CORBISIER, A.; VANHULLE, S. Potential of a Pycnoporus sanguineus laccase in bioremediation of wastewater and kinetic activation in the presence of an anthraquinonic acid dye. Enzyme and Microbial Technology, Amsterdam, v. 41, p. 368-376, 2007.

TUOMELA, M.; VIKAMAN, M.; HATAKKA, A.; ITÄVAARA, M. Biodegradation of lignin in a compost environment: a review. Bioresource Technology, Oxford, v. 72, p. 169-183, 2000.

WALTON, N. J.; MAYER, M. J.; NARBAD A. Molecules of interest: Vanillin. Phytochemistry, Leiden, v. 63, p. 505-515, 2003.

YOSHIDA, A.; TAKENAKA, Y.; TAMAKI, H.; FRÉBORT, I.; ADACHI, O.; KUMAGAI, H. Vanillin formation by microbial amine oxidases from vanillylamine. Journal of Fermentation and Bioengineering, Ishikawa, v. 84, p. 603-605, 1997. 